\title{
A Numerical Simulation of Orthodontic Tooth Movement Produced by a Canine Retraction Spring
}

\author{
Yukio KOJIMA ${ }^{1}$, Toshihiro MIZUNO ${ }^{2}$, Sachio UMEMURA ${ }^{3}$ and Hisao FUKUI ${ }^{4}$ \\ ${ }^{1}$ Department of Mechanical Engineering, Nagoya Institute of Technology, Gokiso-cho, Showa-ku, Nagoya 466-8555, Japan \\ ${ }^{2}$ Department of Mechanical Engineering, Kanagawa Institute of Technology, 1030 Shimo-ogino, Atsugi, Kanagawa 243-0292, \\ Japan \\ ${ }^{3}$ Division of Orthodontics and Dentofacial, Department of Oral Growth and Development, OHU University School of \\ Dentistry, 31-1 Misumido, Tomita-machi, Koriyama, Fukushima 963-8611, Japan \\ ${ }^{4}$ Department of Dental Materials Science, School of Dentistry, Aichi-Gakuin University, 1-100 Kusumoto-cho, Chikusa-ku, \\ Nagoya 464-8650, Japan \\ Corresponding author, Yukio KOJIMA; E-mail: kojima.yukio@nitech.ac.jp
}

Received May 29, 2006/Accepted March 14, 2007

\begin{abstract}
Tooth movements produced by a canine retraction spring were calculated. Although a gable bend and an anti-rotational bend were incorporated into the spring, the canine tipped and rotated initially. Retraction force decreased and moment-toforce ratio increased after the spring legs closed. Then, the initial tipping and rotation began to be corrected. As a result, the canine moved almost bodily after a prolonged period of time. Such tooth movements cannot be estimated from the initial force system. The gable bend decreased tipping movement, but increased rotational movement. On the other hand, the anti-rotational bend decreased rotational movement but increased tipping movement. In other words, one bend decreased the effect of the other, when both bends were incorporated in the spring.
\end{abstract}

Keywords: Orthodontics, Canine retraction, Finite element method

\section{INTRODUCTION}

Canine retraction is one of the basic techniques in orthodontic treatment. A representative method is achieved by using a retraction spring. Closing loops are fabricated in the spring and the teeth move by activation of the loop. This method is friction-free or frictionless technique in contrast to sliding mechanics. However, spring configuration has considerable effects on canine movement. A gable bend must be incorporated into the spring to prevent tipping of the canine. In addition, an anti-rotational bend must be included to prevent rotational movement. These bends produce moments to prevent such unfavorable movements. To estimate an appropriate magnitude of bends, initial moments produced by these bends have been calculated ${ }^{1-3)}$ and measured ${ }^{4.6)}$. Furthermore, a spring has been designed to produce appropriate initial moments ${ }^{7}$.

The authors carried out numerical simulations of orthodontic tooth movements by means of a threedimensional finite element method. It was shown that the initial force system changed considerably with tooth movement ${ }^{8,9}$. Therefore, tooth positions after a prolonged period cannot be estimated from the initial force system. Against this background, we sought to calculate the long-term tooth movements produced by a canine retraction spring. The effects of a gable bend and an anti-rotational bend were discussed from a mechanical point of view.

\section{MATERIALS AND METHODS}

Calculation method for tooth movement

The calculation methods have been mentioned in our previous articles ${ }^{8,9}$. Thus, only the vital calculation methods will be addressed below.

In orthodontic tooth movement, the amount of force acting on a tooth is within several newtons. At this level of force, the initial tooth movement is produced by a deformation of the periodontal ligament (PDL), and is in proportion to the applied force $^{10}$. The tooth and alveolar bone are assumed to be rigid bodies, and the PDL is assumed to be a linear elastic film (Young's modulus: $0.2 \mathrm{MPa}$, Poisson's ration: 0.47 ) with constant thickness of 0.2 $\mathrm{mm}^{8}$. Based on these assumptions, a relationship between applied force (moment) $\boldsymbol{f}$ and tooth displacement $\boldsymbol{u}$ is calculated. This relationship can be written as $\boldsymbol{K} \boldsymbol{u}=\boldsymbol{f}$ where $\boldsymbol{K}$ is a stiffness matrix of the tooth supported by the PDL.

Figure 1 shows a surface model of the tooth used to calculate the matrix $\boldsymbol{K}$. One surface of the PDL is bonded to dentin and the other surface is bonded to the alveolar bone. Normal stresses, $\sigma_{1}, \sigma_{2}, \sigma_{3}$, and shearing stresses, $\tau_{2}, \tau_{3}$, are assumed to act within the PDL. The PDL is divided into small triangular regions, and the stresses in each region are assumed to be identical. Stiffness matrix $\boldsymbol{K}$ is then calculated by the following procedure: (1) unit displacement (translation or rotation) is applied at the bracket position; (2) through tooth kinematics, the deformation of PDL (i.e., strains and stresses in the PDL) are 
calculated for each small region; and (3) integrating the stresses over the root, the total forces and moments acting on the tooth are calculated.

A tooth moves as a result of absorption and apposition of the alveolar bone, which is assumed to occur in a normal direction to the outer surface of the PDL. It is also assumed that the amount of bone remodeling is in proportion to a mean stress $\boldsymbol{\sigma}_{m}\left(=\left(\boldsymbol{\sigma}_{1}+\boldsymbol{\sigma}_{2}+\boldsymbol{\sigma}_{3}\right) / 3\right.$ in the PDL. The amount of absorption (apposition) per unit stress and unit time was denoted by a coefficient $C$. This coefficient is assumed to be the same in all teeth. At any given

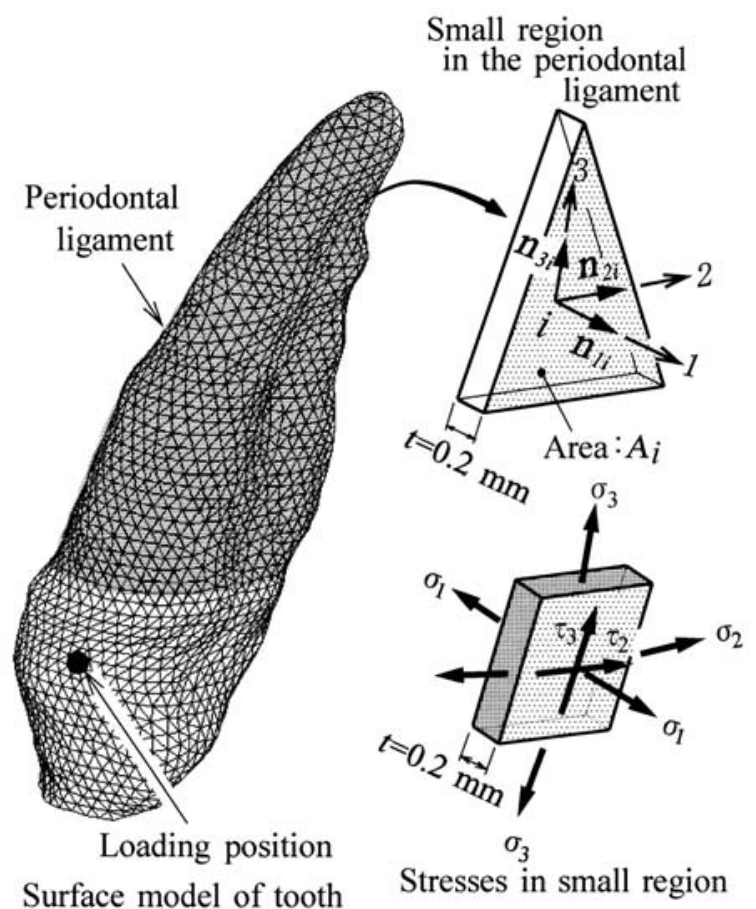

Fig. 1 Surface model of tooth for calculating relationship between applied force and tooth displacement.

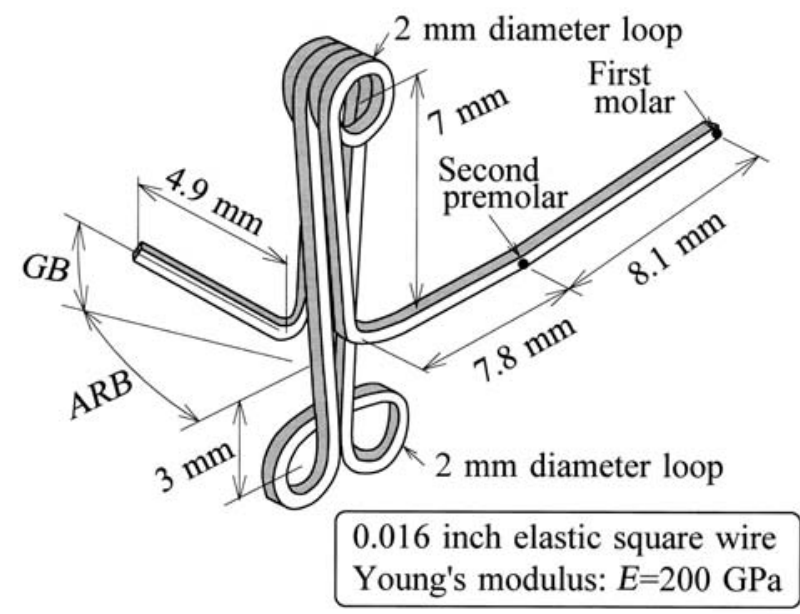

Fig. 2 Configuration of canine retraction spring with gable bend and anti-rotational bend. time $T$, a tooth movement in the next small time increment $\Delta T$ is calculated by the following procedure: (1) absorption of the alveolar bone in each small region, $\Delta t$, is calculated as $\Delta t=-C \sigma_{m} \Delta T$; (2) normal stress $\Delta \sigma_{1}$ required to move a tooth by the distance $\Delta t$ in each small region is calculated as $\Delta \sigma_{1}=-C \sigma_{m} E^{\prime} \Delta T / t . \quad E^{\prime}$ is $E^{\prime}=E(1-\mathbf{v}) /((1+\mathbf{v})(1-2 \mathbf{v}))$, where $E$ and $v$ are Young's modulus and Poisson's ratio of the PDL respectively; (3) tooth moving force $\Delta \boldsymbol{R}$ (i.e., total forces and moments to move the tooth) is calculated by integrating $\Delta \mathbf{\sigma}_{1}$ over the root; (4) displacement $\boldsymbol{\Delta} \boldsymbol{u}$ of the tooth produced by $\boldsymbol{\Delta} \boldsymbol{R}$ (i.e., tooth movement in $\Delta T$ ) is calculated using $K \Delta \boldsymbol{u}=\Delta \boldsymbol{R}$.

Tooth movement $\boldsymbol{\Delta} \boldsymbol{u}$ for each tooth is calculated from the stress distribution in the PDL, and then the teeth are moved by $\boldsymbol{\Delta} \boldsymbol{u}$. By repeating this procedure, the tooth positions at a given time $T$ can be obtained. As indicated in the equations above, the absorption of alveolar bone or the tooth movement is controlled by a parameter $C T$. At present, since the value of $C$ is uncertain, $C T$ is used to indicate the progress of tooth movement.

\section{Calculation model}

At the left maxillary, a second premolar and a first molar are used as anchorage, and a canine is retracted in the distal direction. Surface models of the teeth are made based on a dental study model (AM-10, Nissin Dental Products Inc., Kyoto, Japan). Configuration of the retraction spring is adapted from a commercial retraction spring (Maxillary Cuspid Retractor, Left A-521, Rocky Mountain Morita Corp., Tokyo, Japan), as shown in Fig. 2. This spring has low stiffness due to the multiple loops. It is made from a 0.016 -inch elastic square wire of cobalt-chromium-nickel-molybdenum alloy (Young's modulus: $200 \mathrm{GPa}$, Poisson's ratio: 0.3).

The spring is activated to open the spring legs by $3 \mathrm{~mm}$ distance. Angles of gable bend $G B$ and anti-rotational bend $A R B$ are changed. The spring and brackets are ligated firmly to prevent sliding against each other. It is assumed that the spring is not deformed in the bracket slot. In clinical situations, there is clearance between the spring and the bracket slot, and between the spring and the ligature wire. These clearances are ignored in the present calculation, and so forces and moments (torque) of the spring are completely transmitted to the bracket.

\section{RESULTS}

In the spring with neither the gable bend nor antirotational bend $(G B=0$, and $A R B=0)$, tooth movements with time $C T$ are shown in Figs. 3(a), (b), and (c). Distributions of mean stress $\sigma_{m}$ in the PDL are 


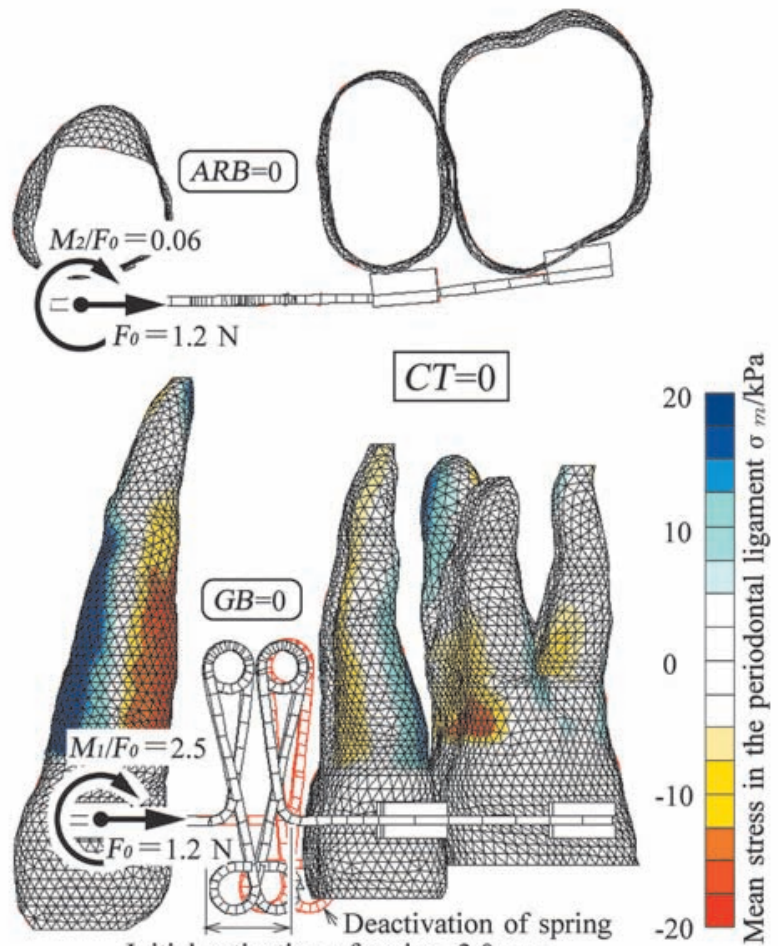

Initial activation of spring $=3.0 \mathrm{~mm}$

(a) Initial activation
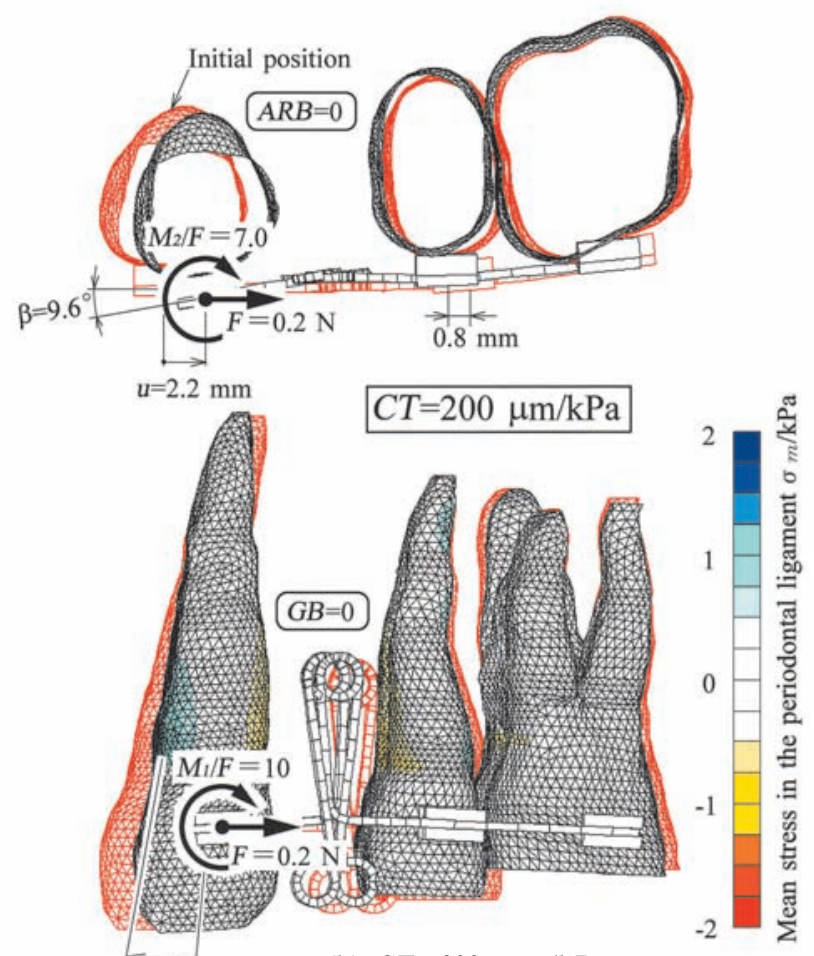

$\underset{\alpha=5.9^{\circ}}{\longrightarrow} \quad$ (b) $C T=200 \mu \mathrm{m} / \mathrm{kPa}$ indicated by color contours. At initial activation $(C T=0)$, a force of $F_{0}=1.2 \mathrm{~N}$ acted on the canine and moment-to-force ratios became $M_{1} / F_{0}=2.5$ and $M_{2} / F_{0}$ =0.06. The moments $M_{1}$ and $M_{2}$ tended to prevent tipping and rotation respectively. Stress in the PDL of canine was higher than those of the anchor teeth. At $C T=200 \mu \mathrm{m} / \mathrm{kPa}$, the canine moved distally by $u=2.2 \mathrm{~mm}$ and the anchor teeth moved mesially by $0.8 \mathrm{~mm}$. At this time, activation of the spring (gap between spring legs) became almost zero. The canine tipped by $a=5.9^{\circ}$ from the buccal viewpoint, and it rotated by $\beta=9.6^{\circ}$ on the occlusal plane. The center of tipping movement was located at one-third root length from the apex. After a prolonged period $(C T=1000 \mu \mathrm{m} / \mathrm{kPa})$, both the displacement and tipping angle of canine hardly changed $(u=2.2 \mathrm{~mm}, \boldsymbol{\alpha}=$ $\left.5.7^{\circ}\right)$. However, the rotational angle of canine decreased to $\beta=5.7^{\circ}$. The force acting on the canine $F$ decreased as the teeth moved, and the activated spring went back to the initial configuration (Fig. 4). With the decrease in $F$, moment-toforce ratios $M_{1} / F$ and $M_{2} / F$ increased rapidly. Therefore, the rotational angle $\beta$, which increased initially, decreased with time CT (Fig. 5).

In the spring with both the gable bend and the anti-rotational bend $\left(G B=30^{\circ}\right.$, and $\left.A R B=50^{\circ}\right)$, tooth movements are shown in Figs. 6(a), (b), and (c). Although the amount of activation was the same as that in the case without both bends, the initial force
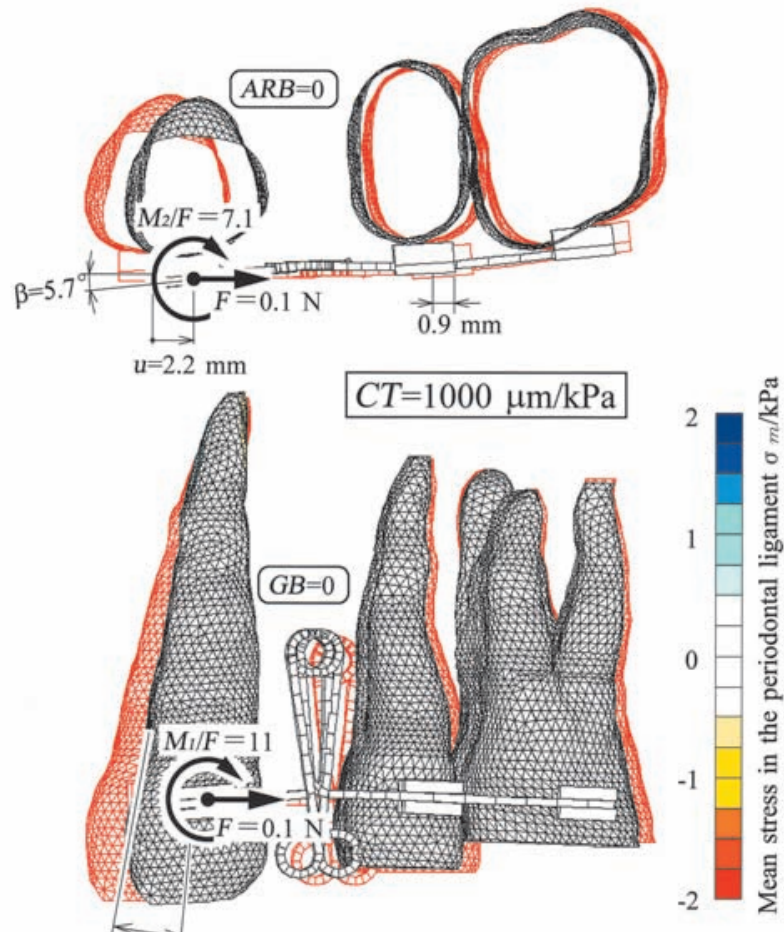

$\underset{\alpha=5.7^{\circ}}{\longrightarrow} \quad$ (c) $C T=1000 \mu \mathrm{m} / \mathrm{kPa}$

Fig. 3 Tooth movement produced by retraction spring without both bends: (a) Initial activation; (b) $C T=200 \mu \mathrm{m} / \mathrm{kPa}$; and (c) $C T=1000 \mu \mathrm{m} / \mathrm{kPa}$. 


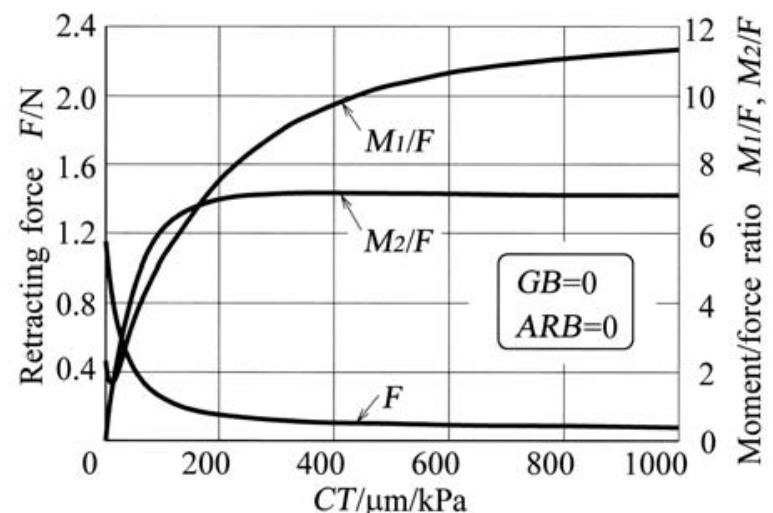

Fig. 4 Variation of force and moment-to-force ratios acting on canine with time $C T$ (without both bends).

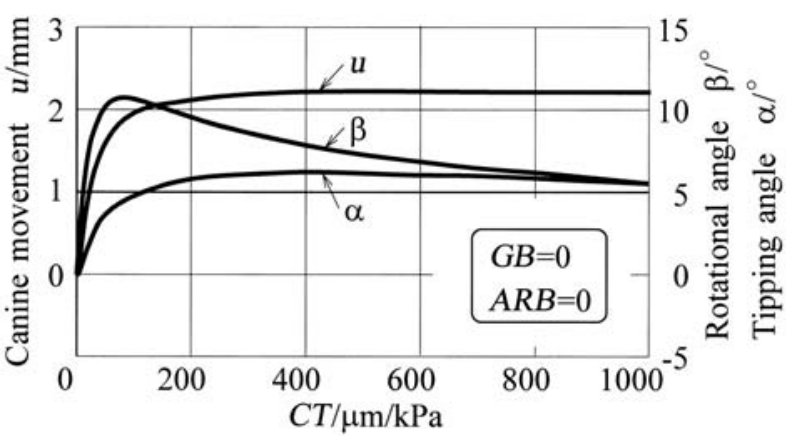

Fig. 5 Variation of translation, tipping angle, and rotational angle of canine with time $C T$ (without both bends).

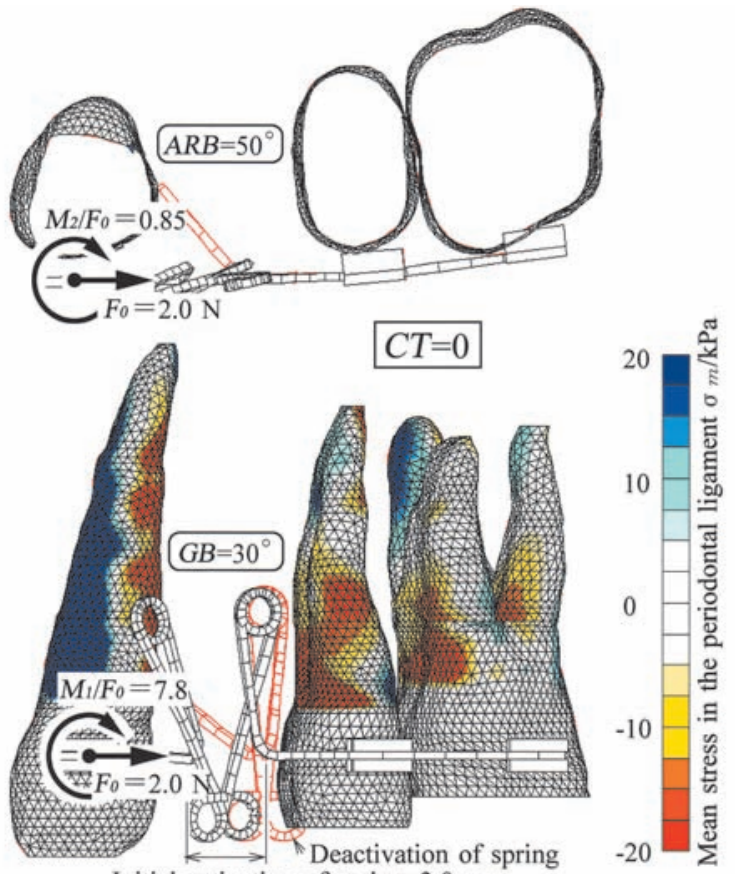

Initial activation of spring $=3.0 \mathrm{~mm}$

(a) Initial activation acting on the canine became almost twice $\left(F_{0}=2.0 \mathrm{~N}\right)$, and initial moment-to-force ratios increased to $M_{1} /$ $F_{0}=7.8$ and $M_{2} / F_{0}=0.85$. At $C T=200 \mu \mathrm{m} / \mathrm{kPa}$ when the spring legs almost closed, the canine moved distally by $u=2.5 \mathrm{~mm}$ and the anchor teeth moved mesially by $0.9 \mathrm{~mm}$. At this time, the canine
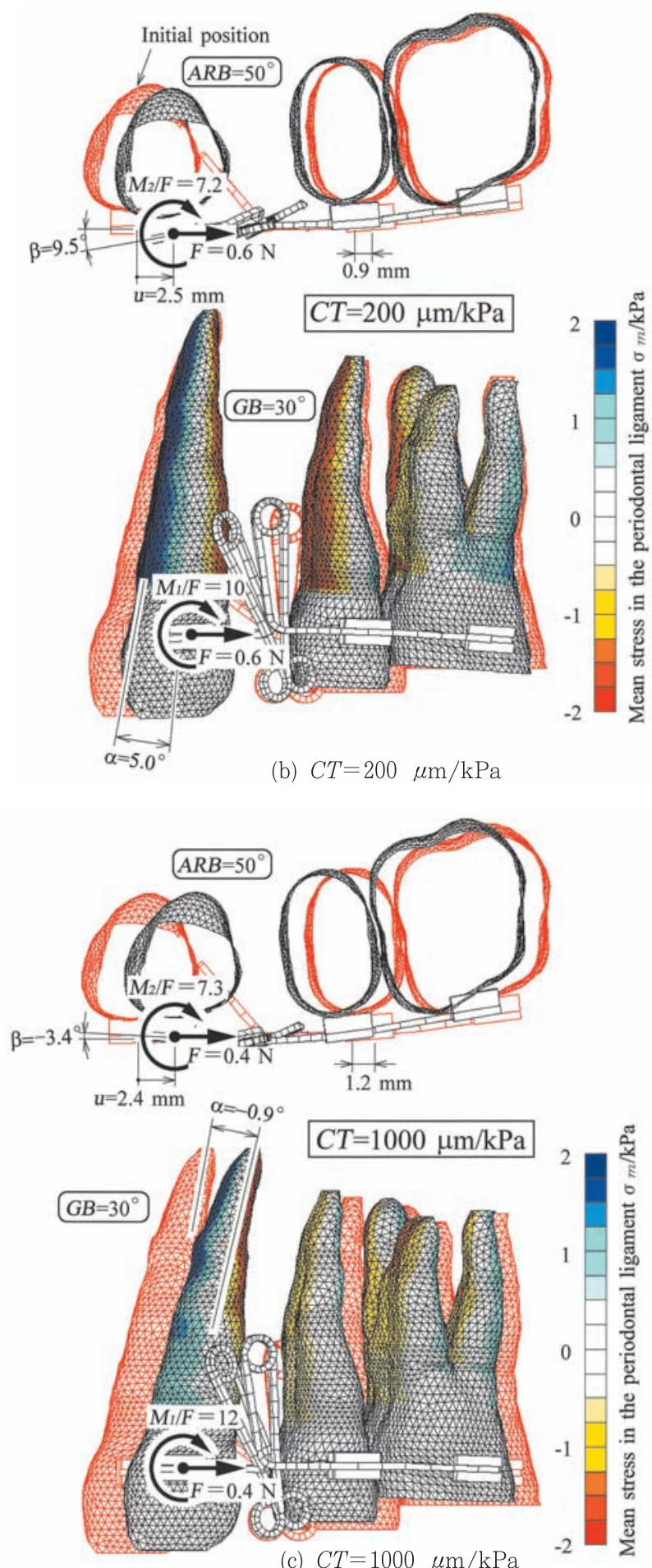

(c) $C T=1000 \mu \mathrm{m} / \mathrm{kPa}$

Fig. 6 Tooth movement produced by retraction spring with gable bend and anti-rotational bend: (a) Initial activation; (b) $C T=200 \mu \mathrm{m} / \mathrm{kPa}$; and (c) $C T=1000 \mu \mathrm{m} / \mathrm{kPa}$. 


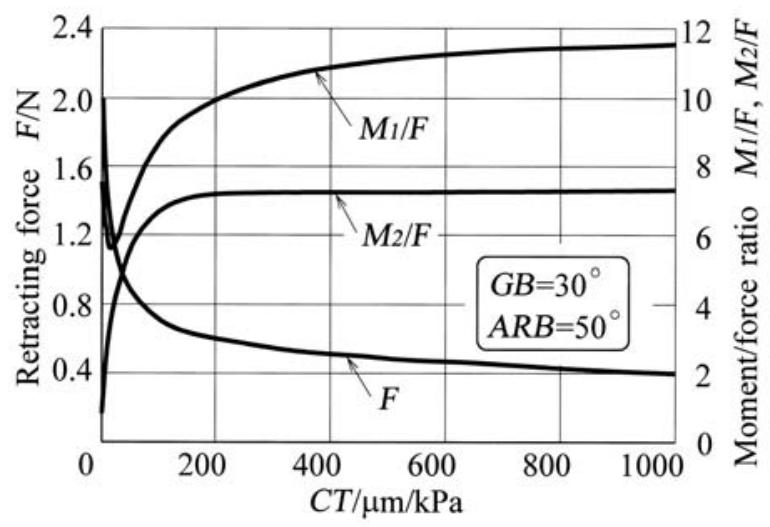

Fig. 7 Variation of force and moment-to-force ratios acting on canine with time $C T$ (with gable bend and anti-rotational bend).

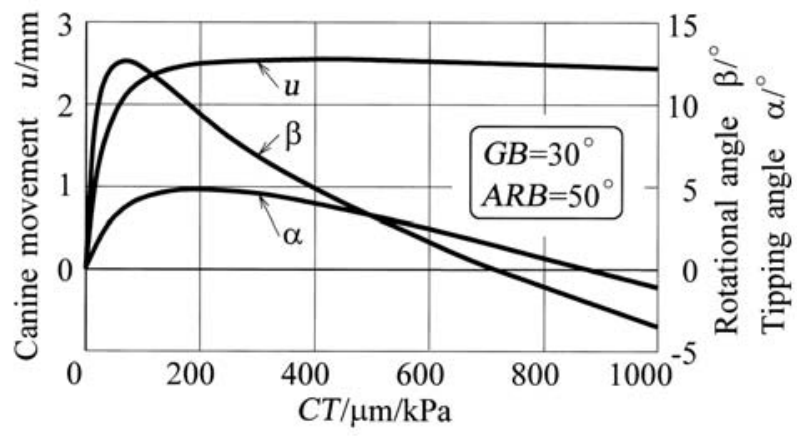

Fig. 8 Variation of translation, tipping angle, and rotational angle of canine with time $C T$ (with gable bend and anti-rotational bend).

tipped by $a=5.0^{\circ}$ and rotated by $\beta=9.5^{\circ}$. These values were about the same as those in the case without both bends. After a prolonged period $(C T=$ $1000 \mu \mathrm{m} / \mathrm{kPa}$ ), the displacement hardly changed $(u=2.4 \mathrm{~mm})$. However, the tipping and rotational angles of canin decreased to $\alpha=-0.9^{\circ}$ and $\beta=$ - $3.4^{\circ}$ respectively. Moment-to-force ratios $M_{1} / F$ and $M_{2} / F$ increased rapidly, when the force acting on the canine $F$ decreased with time $C T$ (Fig. 7). After the spring legs closed $(C T>100 \mu \mathrm{m} / \mathrm{kPa})$, the amount of $F$ was larger than that in the case without both bends. The tipping and rotational angles of canine, $\alpha$ and $\beta$, decreased below zero and become negative values (Fig. 8).

When angles of the gable bend $G B$ and antirotational bend $A R B$ were changed respectively, the force $F_{0}$ acting on the canine at initial activation, the tipping angle $\alpha$, and the rotational angle $\beta$ of the canine at $C T=1000 \mu \mathrm{m} / \mathrm{kPa}$ are shown in Figs. 9 and 10. These figures show the effects of gable bend and anti-rotational bend on tooth movement. The force $F_{0}$ increased with an increase in $G B$, when only the gable bend was incorporated (Fig. 9, $A R B=0$ ). When $F_{0}$ became $1.92 \mathrm{~N}$ at $G B=30^{\circ}$, the maximum

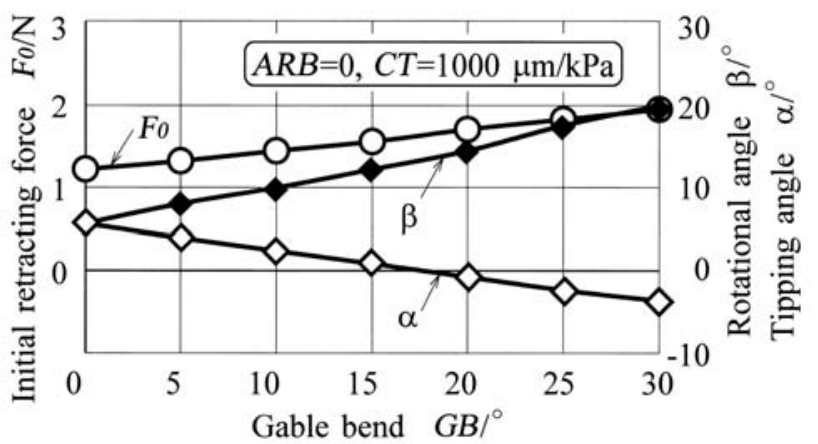

Fig. 9 Variation of initial force, tipping angle, and rotational angle of canine with gable bend.

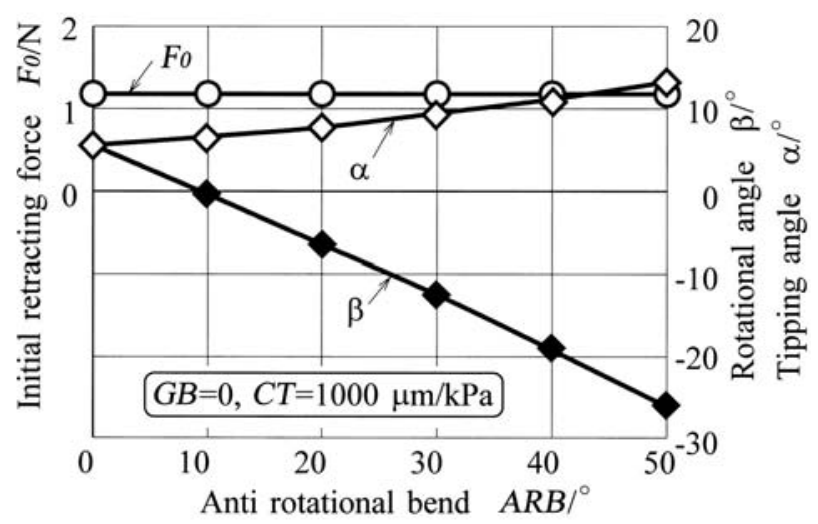

Fig. 10 Variation of initial force, tipping angle, and rotational angle of canine with anti-rotational bend.

equivalent stress of $1790 \mathrm{MPa}$ was produced in the spring. The tipping angle a decreased but the rotational angle $\beta$ increased in proportion to $G B$. When only the anti-rotational bend was incorporated (Fig. 10, $G B=0$ ), the force $F_{0}$ hardly changed with increase in $A R B$. The rotational angle $\beta$ decreased but tipping angle $\alpha$ increased in proportion to $A R B$. The change in $\beta$ was considerable.

\section{DISCUSSION}

Finite element methods have been used to calculate stress in the PDL during initial tooth movement ${ }^{11-15)}$. Recently, long-term orthodontic tooth movements for a single-root tooth were calculated ${ }^{16,17}$. Furthermore, we proposed a simulation method for typical clinical situations where many teeth connected with a wire moved at the same time ${ }^{899}$. The same method was used in the present study. Simple assumptions were adopted as a first step for simulation of this nature; otherwise uncertain factors included in the calculation would only complicate the method and results. These assumptions have been discussed in a previous article $^{9 \text {. }}$. 
The human periodontal ligament has a fiber structure and anisotropy. Furthermore, the stressstrain relation is nonlinear ${ }^{18)}$. The thickness of PDL varies at different positions in the root ${ }^{19)}$. These factors have been included in recent calculations of the stress distribution in $\mathrm{PDL}^{20.21}$, but how these factors affect tooth movement have not been clarified. In this study, therefore, it was assumed that the PDL was a linear elastic film and its thickness was the same in all teeth.

The most important factor affecting tooth movement is the bone remodeling law that describes the relationship between the apposition of the alveolar bone and the mechanical stimulus. In particular, an excessive orthodontic force produces hyalinization of the PDL and undermining bone resorption, impeding efficient bone remodeling. This phenomenon suggests that there is a maximum stress above which the bone remodeling rate decreases. However, this phenomenon has not been fully confirmed ${ }^{22)}$, and experimental data required for this calculation have not been found. If useful data were available, we would be able to include this effect in our calculation. Under these circumstances, we simply assumed that the resorption rate was proportional to the mean stress in the PDL. The calculated results in this study are valid only in a light force range wherein bone remodeling occurs depending on stress.

Although both the gable bend and anti-rotational bend were incorporated into the spring, the canine tipped and rotated immediately after activation. Initial moment-to-force ratios produced by both the bends were not sufficient to prevent tipping and rotation. In the case without both bends, the initial tipping and rotation remained after a prolonged period. On the other hand, when both bends were included, the initial tipping and rotation were corrected over time. After a prolonged period, the canine became uprigh, and was derotated. The final position of teeth depended on tooth movements during the period when the retracting force was decreasing and the moment-to-force ratios were increasing. The initial force system changed with tooth movement. Therefore, the final position of teeth cannot be estimated from the initial force system.

When gable bend $G B$ was increased, tipping angle a of canine decreased (Fig. 9). However, retraction force $F_{0}$ increased. An excessive retraction force will produce hyalinization of the PDL and undermining bone resorption, thereby impeding efficient tooth movement. This increase in retraction force makes it impossible to incorporate a large gable bend. In addition, high stress was produced in the spring by the gable bend. At $G B=30^{\circ}$, the stress in the spring became $1790 \mathrm{MPa}$, and this value was close to the elastic limit of cold-worked cobalt-chromium-nickel- molybdenum alloy (2000 MPa). On the other hand, the rotational angle of canine, $\beta$, increased in proportion to GB. Therefore, the gable bend reduced the effect of anti-rotational bend.

When anti-rotational bend $A R B$ was increased, rotational angle of canine, $\beta$, decreased, whereas retraction force $F_{0}$ hardly changed (Fig. 10). An excessive anti-rotational bend produced opposite (negative) rotation. On the other hand, the tipping angle of canine, $\mathbf{a}$, increased in proportion to $A R B$. Therefore, the anti-rotational bend reduced the effect of the gable bend.

As discussed above, the gable bend and antirotational bend prevented tipping and rotation of the canine respectively. However, when both bends were incorporated into the spring, one bend decreased the effect of the other. This phenomenon has been examined in clinical conditions by Nishikawa et $a l^{23}$. In the case without gable bend $(G B=0)$, the rotational angle of canine could be reduced to zero by incorporating an anti-rotational bend of $A R B=$ $10^{\circ}$ alone (Fig. 10). When a gable bend was added to prevent tipping, the rotational angle of canine increased. Finally, when the angles of antirotational bend and gable bend were increased to $A R B=50^{\circ}$ and $G B=30^{\circ}$ respectively, both the angles of tipping and rotation of canine could be reduced to about zero (Fig. 6(c)). The same effect is expected in different retraction springs, and the effect will be noticeable in clinical situations.

Results obtained in this study were reasonable from a mechanical point of view; however, they have not been confirmed from a clinical point of view. This confirmation is left for a future work. Simplistic assumptions used in the present calculation would be insufficient to predict tooth movements in clinical situations. If the calculated results were different from clinical tooth movements, the assumptions should be reconsidered and modified. For example, clearance between the spring and bracket slot was ignored in the present calculation. However, clearances exist in clinical situations and torque of the spring may not be transmitted to the bracket. As a result, the canine will tip in the bucco-lingual direction. Such effects of clearance on tooth movement should be considered in the future study.

In a restricted condition where assumptions used in the present calculation are valid, tooth movement produced by a canine retraction spring could be calculated. From the calculated results, the mechanical effects of the gable bend and anti-rotational bend could be clarified. Furthermore, not only canine movement, but anchor teeth movement also, could be estimated quantitatively. Therefore, the simulation method in this study should be utilized to examine which kind of retraction method is appropriate, or to design springs for efficient canine retraction. 


\section{REFERENCES}

1) DeFranco JC, Koenig HA, Burstone CJ. Threedimensional large displacement analysis of orthodontic appliances. J Biomech 1976; 9: 793-801.

2) Haskell BS, Spencer WA, Day M. Auxiliary springs in continuous arch treatment: Part 1. An analytical study employing the finite-element method. Am J Orthod Dentofacial Orthop 1990; 98: 387-397.

3) Siatkowski RE. Continuous arch wire closing loop design, optimization, and verification, Part I. Am J Orthod Dentofacial Orthop 1997; 112: 393-402.

4) Burstone CJ, Koenig HA. Optimizing anterior and canine retraction. Am J Orthod 1976; 70: 1-19.

5) Menghi C, Planert J, Melsen B. 3-D experimental identification of force systems from orthodontic loops activated for first order corrections. Angle Orthod 1999; 69: 49-57.

6) Chen J, Markham DL, Katona TR. Effects of T-loop geometry on its forces and moments. Angle Orthod 2000; 70: 48-51.

7) Raboud DW, Faulkner MG, Lipsett AW, Haberstock DL. Three-dimensional effects in retraction appliance design. Am J Orthod Dentofacial Orthop 1997; 112: 378-392.

8) Kojima Y, Fukui H. A numerical analysis of tooth movement by orthodontic forces. J Jpn Soc Dent Mat and Dev 2002; 21: 40-48.

9) Kojima Y, Fukui H. Numerical simulation of canine retraction by sliding mechanics. Am J Orthod Dentof acial Orthop 2005; 127: 542-551.

10) Muhlemann HR. 10 years of tooth-mobility measurements. J Periodont 1960; 31: 110-122.

11) Tanne K, Sakuda M, Burstone CJ. Three-dimensional finite element analysis for stress in the periodontal tissue by orthodontic forces. Am J Orthod Dent of acial Orthop 1987; 92: 499-505.

12) Jeon PD, Turley PK, Moon HB, Ting K. Analysis of stress in the periodontium of the maxillary first molar with a three-dimensional finite element model. Am J Orthod Dentofacial Orthop 1999; 115: 267-274.

13) Chang YI, Shin SJ, Baek SH. Three-dimensional finite element analysis in distal en masse movement of the maxillary dentition with the multiloop edgewise archwire. Eur J Orthod 2004; 26: 339-345.

14) Jeon PD, Turley PK, Ting K. Three-dimensional finite element analysis of stress in the periodontal ligament of the maxillary first molar with simulated bone loss. Am J Orthod Dentofacial Orthop 2001; 119: 498-504.

15) Puente MI, Galban L, Cobo JM. Initial stress differences between tipping and torque movements. A three-dimensional finite element analysis. Eur J Orthod 1996; 18: 329-339.

16) Bourauel C, Vollmer D, Jager A. Application of bone remodeling theories in the simulation of orthodontic tooth movements. J Orofac Orthop 2000; 61: 266-279.

17) Schneider J, Geiger M, Sander FG. Numerical experiments on long-time orthodontic tooth movement. Am J Orthod Dentofacial Orthop 2002; 121: 257-265.

18) Toms SR, Lemons JE, Bartolucci AA, Eberhardt AW. Nonlinear stress-strain behavior of periodontal ligament under orthodontic loading. Am J Orthod Dentofacial Orthop 2002; 122: 174-179.

19) Coolidge ED. The thickness of the human periodontal membrane. J Am Dent Asso Dent Cos 1937; 24: 12601270.

20) Qian H, Chen J, Katona TR. The influence of PDL principal fibers in a 3-dimensional analysis of orthodontic tooth movement. Am J Orthod Dentofacial Orthop 2001; 120: 272-279.

21) Toms SR, Eberhardt AW. A nonlinear finite element analysis of the periodontal ligament under orthodontic tooth loading. Am J Orthod Dentofacial Orthop 2003; 123: 657-665.

22) Ren Y, Maltha JC, Kuijpers-Jagtman AM. Optimum force magnitude for orthodontic tooth movement: a systematic literature review. Angle Orthod 2003; 73: 86-92.

23) Nishikawa H, Yamamoto K, Mikami T, Hayashi S, Nakamura S. Measurement of tooth movement during orthodontic treatment and model analysis of orthodontic springs. Techn Rep IEICE (Institute of Electronics, Information and Communication Engineers) 1988; MBE88: 35-42. 